\title{
AVALIAÇÃO DE FISSURAS EM EDIFICAÇÕES DE CONCRETO ARMADO: ESTUDO DE CASO EM UMA RESIDÊNCIA UNIFAMILIAR
}

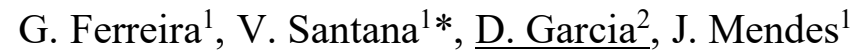 \\ *Autor de Contato: vanessa.santana@aluno.ufop.edu.br \\ ${ }^{1}$ Departamento de Engenharia Civil, Escola de Minas, Universidade Federal de Ouro Preto, Ouro Preto, Brasil \\ ${ }^{2}$ Departamento de Engenharia Civil, Faculdade de Engenharia, Universidade Federal de Juiz de Fora, Juiz de Fora, \\ Brasil
}

\begin{abstract}
RESUMO
O presente trabalho investiga as causas mais frequentes de fissuras em edificações brasileiras, bem como apresenta métodos de prevenção e reparo. Para tal, foi realizado um estudo de caso de uma edificação unifamiliar na cidade de Ouro Preto, Minas Gerais. Identificaram-se as manifestações patológicas na edificação que foram associadas a variações térmicas e higroscópicas e a erros de execução. $\mathrm{O}$ estudo contribui ainda com indicações e recomendações técnicas para a recuperação das manifestações patológicas encontradas no caso estudado. Os resultados podem auxiliar na solução de fissuras comuns de edificações residenciais autoconstruídas, além de evidenciar a importância da concepção dos projetos e do acompanhamento da execução da obra por profissionais qualificados.
\end{abstract}

Palavras-chave: Manifestações patológicas; Fissuras; Trincas; Rachaduras; Recuperação.

\begin{abstract}
The present work investigates the most frequent causes of cracks in Brazilian buildings and presents methods of prevention and repair. Therefore, a case study of a single-family building in
\end{abstract}


the city of Ouro Preto, Minas Gerais, was carried out. Pathological manifestations in the building were identified, which were associated with thermal and hygroscopic variations and execution errors. The study also contributes with indications and technical recommendations for the recovery of the pathological manifestations found in the case studied. The results can assist in the solution of common cracks in self-constructed residential buildings, in addition to highlighting the importance of project design and monitoring of the work carried out by qualified professionals.

Keywords: Pathological manifestations; Fissures; Cracks; Recovery

\section{RESUMEN}

El presente trabajo investiga las causas más frecuentes de grietas en edificios brasileños, así como presenta métodos de prevención y reparación. Para ello, se realizó un estudio de caso de un edificio unifamiliar en la ciudad de Ouro Preto, Minas Gerais. Se identificaron manifestaciones patológicas en el edificio, las cuales se asociaron con variaciones térmicas e higroscópicas y errores de ejecución. El estudio también aporta indicaciones y recomendaciones técnicas para la recuperación de las manifestaciones patológicas encontradas en el caso estudiado. Los resultados pueden ayudar en la solución de grietas comunes en edificios residenciales autoconstruidos, además de resaltar la importancia del diseño del proyecto y el seguimiento de la ejecución de la obra por profesionales calificados.

Palabras clave: Manifestaciones patológicas; Fisuras; Grietas; Recuperación.

\section{INTRODUÇÃO}


A norma brasileira de desempenho de edificações, NBR 15575 (ABNT, 2013), define como vida útil de uma edificação o período de tempo em que a construção e seus componentes cumprem as funções para as quais foram projetadas e atendem aos níveis de desempenho previstos. Segundo a mesma normativa, o bom desempenho das habitações implica que aspectos como segurança para uso e operação, estanqueidade, conforto térmico e acústico, higiene e funcionalidade sejam assegurados.

Entretanto, por diversos motivos, muitas edificações tendem a apresentar defeitos ou vícios, chamados manifestações patológicas, de forma precoce. De acordo com Silva (2011), as patologias construtivas podem ser resultado de projetos deficientes, de execuções malfeitas ou podem ser adquiridas ao longo da vida útil da estrutura por uso indevido ou falta de manutenção adequada. $\mathrm{O}$ mau funcionamento das estruturas pode oferecer riscos à saúde, produtividade e bem estar dos usuários. Além disso, em casos mais extremos, é possível que manifestações patológicas levem as edificações à ruína, causando o risco de perda de vidas e prejuízos econômicos.

A recuperação de patologias em edificações pode ser obtida a partir de manutenções corretivas dos elementos construtivos. Segundo a NBR 15575 (ABNT, 2013), estas se caracterizam por serviços que demandam ação ou intervenção para permitir a continuidade de uso da edificação. Dessa forma, este tipo de manutenção tem o objetivo de diagnosticar, proteger, reforçar e reparar os elementos que eventualmente apresentaram manifestações patológicas. Estas intervenções podem apresentar um alto custo ao proprietário da edificação. Pode-se associar um custo 125 vezes maior que o custo da adoção de medidas corretas da etapa de projeto, a depender da natureza e da magnitude das patologias incidentes (Souza \& Ripper, 1998; Neves \& Vázquez, 2020).

Dentre os diversos tipos de patologias, podem-se destacar as trincas, fissuras e rachaduras. Elas ocorrem, pois, os materiais constituintes de uma edificação são susceptíveis à variação de temperatura, à retração e à agressão ao meio ambiente (Neves \& Vázquez, 2020). Segundo Veiga (1998), a restrição a essa movimentação origina tensões no próprio material ou em seu contato com outros. Assim, essas aberturas surgem para aliviar as solicitações quando os esforços originados forem maiores que os resistentes.

$\mathrm{O}$ aparecimento de fissuras, trincas e rachaduras nas edificações é um dos problemas patológicos que mais atraem a atenção do usuário da edificação (Neves \& Vázquez, 2020). Essas podem despertar sensação de insegurança, desconforto visual e mental nos usuários da edificação em que se acomete. Além disso, elas podem comprometer a estanqueidade, a vedação contra o ambiente externo, o isolamento térmico e acústico e a estética dos ambientes a depender da sua extensão (Sahade, 2005).

Tais manifestações patológicas podem ser classificadas de acordo com o tamanho da abertura da seguinte forma: fissuras são as aberturas menores que $0,5 \mathrm{~mm}$; trincas, entre $0,5 \mathrm{e} 1,5 \mathrm{~mm}$; e rachaduras, entre 1,5 e 5,0 mm (Oliveira, 2012). Neste artigo, caso não seja especificado o tamanho da abertura, trataremos estas manifestações por "fissura". De acordo com Sahade (2005), tais aberturas podem ser classificadas quanto à forma de se manifestar (aparência), como geométricas ou mapeadas. Segundo o mesmo autor, as fissuras geométricas são aproximadamente lineares, seguindo uma direção predominante e normalmente derivam da movimentação diferencial do substrato. As fissuras mapeadas, por sua vez, ocorrem em todas as direções simultaneamente, geralmente ocasionadas pela retração do material.

As fissuras também podem ser classificadas conforme a sua atividade. Segundo a NBR 15575 (ABNT, 2013), estas podem ser classificadas como ativas quando apresentam variações sensíveis na abertura ao longo do tempo, e passivas quando possuem abertura constante, ou seja, não se expandem nem se retraem mais. De acordo com Sahade (2005), caso essa oscilação seja sazonal, as fissuras ativas normalmente não indicam problemas na estrutura da edificação. Porém, no caso 
de a variação da abertura ser progressiva (somente se ampliam com o passar do tempo), deve-se verificar a possibilidade de problemas estruturais que devem ser corrigidos de forma imediata. (Sahade, 2005)

Dessa forma, independentemente do tipo, é fundamental a análise da patologia observada e a sua correção sempre que possível. De acordo com Sahade (2005), as técnicas de recuperação de elementos fissurados dependem das características das fissuras. É fundamental que a solução empregada seja compatível com o problema e com as características construtivas da edificação (Lordsleem, 1997).

Entretanto, identificar as causas de uma fissura é uma tarefa complexa, pois, segundo Thomaz (1989), o mesmo problema pode dar origem a diversas configurações de fissuras. Além disso, uma fissura pode se originar por um somatório de diferentes causas. Ainda assim, é imprescindível que antes da adoção de medidas visando à recuperação da fissura, seja identificada e sanada a causa (ou causas) que a originaram (Lordsleem, 1997).

Neste contexto, o presente trabalho busca investigar as manifestações de fissuras em edificações, analisando suas causas e efeitos, bem como investigar possíveis soluções para um caso real na cidade de Ouro Preto, Minas Gerais.

\section{METODOLOGIA}

O presente estudo consiste na análise de uma residência situada em Ouro Preto, Minas Gerais. A propriedade em estudo é uma edificação de uso residencial unifamiliar de um pavimento que foi construída para uma família de cinco pessoas. O planejamento da obra foi iniciado no ano de 2007 com a elaboração do projeto arquitetônico por uma profissional de arquitetura e urbanismo. Os projetos estrutural, hidrossanitário e elétrico foram elaborados por um engenheiro civil.

A construção foi iniciada em abril de 2008 e foi finalizada em junho do ano seguinte. A obra foi realizada por três pedreiros (incluindo um dos proprietários da residência) e dois serventes, sem contar com acompanhamento técnico. De acordo com a proprietária, que acompanhou todo o processo de elaboração e aprovação dos projetos e de construção da edificação, os projetos não foram integralmente seguidos. A edificação é situada no nível da rua, foi construída com estrutura em concreto armado e alvenaria de vedação em tijolo furado e possui $103 \mathrm{~m}^{2}$ de área construída.

A edificação objeto deste estudo foi escolhida devido a sua representatividade, uma vez que as fissuras nela existentes são usuais nos lares brasileiros, especialmente àqueles resultantes de autoconstrução, como o presente caso. Para o estudo da origem das manifestações patológicas da residência, além de uma inspeção visual em visita realizada ao imóvel, foi realizada uma anamnese com a proprietária da edificação no dia 16 de setembro de 2019.

$\mathrm{Na}$ visita técnica foram identificadas 10 fissuras que serão ilustradas e classificadas a seguir de acordo com as possíveis causas apresentadas. Na data da inspeção, a temperatura aproximada era de $28^{\circ} \mathrm{C}$ com elevada umidade relativa do ar. Ocorreram também pancadas de chuva durante a semana.

\section{RESULTADOS}

\subsection{Descrição do imóvel e da vizinhança}

A edificação estudada (Figura 1, demarcada em amarelo) faz divisa com a Lagoa do Gambá à esquerda e com um lote vago à direita. A existência da lagoa e o clima chuvoso da região central mineira contribuem com a alta umidade e elevado nível de água da região onde está situada a edificação. A proprietária sustentou essa hipótese ao afirmar que "durante a construção percebeuse que a água aparecia muito fácil no terreno". 


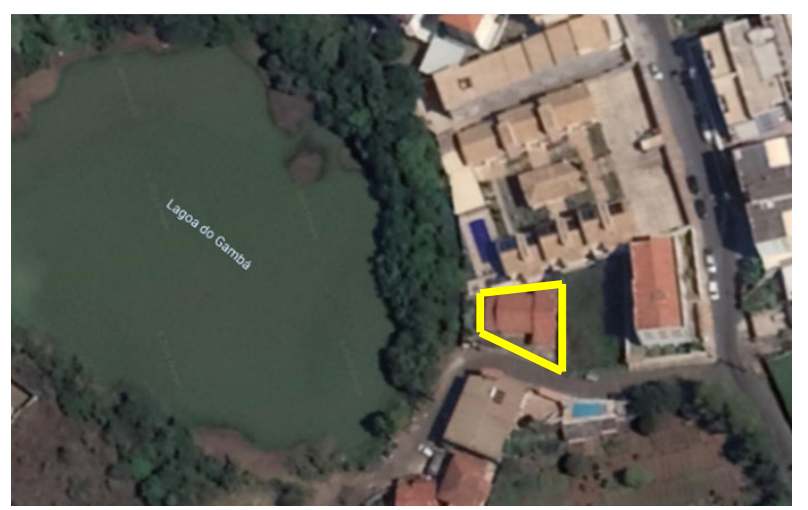

Figura 1. Vista aérea da edificação estudada (demarcada em amarelo) e da sua vizinhança.

Fonte: Google Earth, 2020.

$\mathrm{Na}$ parte posterior da edificação há uma casa de dois pavimentos e um prédio de quatro pavimentos. Assim como o imóvel estudado, a edificação vizinha respeita o afastamento mínimo previsto pela lei de Uso e Ocupação do Solo de Ouro Preto, que é igual a 1,50 m. Entretanto, o prédio não respeita o afastamento previsto por lei e avança sobre o muro. Desta forma, a edificação somente recebe incidência da luz solar diretamente nas fachadas frontal e posterior. Sabe-se que a variação de temperatura e umidade são fenômenos que podem causar patologias nas edificações (Souza M. F., 2008; Ribeiro \& Volkweis, 2016).

A rua onde está situada a edificação estudada apresenta um pequeno fluxo de veículos e, em geral, carros de passeio. Dessa forma, considerando que a edificação tem afastamento de $4,5 \mathrm{~m}$ em relação à rua ( $3 \mathrm{~m}$ de recuo frontal adicionado a $1,5 \mathrm{~m}$ de passeio), a vibração causada pelo trânsito de veículos na região será desprezada para análise das patologias encontradas.

\subsection{Identificação das patologias de fissuras na edificação}

Durante a inspeção visual da edificação, foram detectadas 10 fissuras localizadas em diferentes dependências. A Figura 2 apresenta croqui do imóvel contendo o local onde foram identificadas as fissuras, juntamente com a legenda dos símbolos utilizados para indicar a possível causa da patologia, conforme será discutido na sequência. 


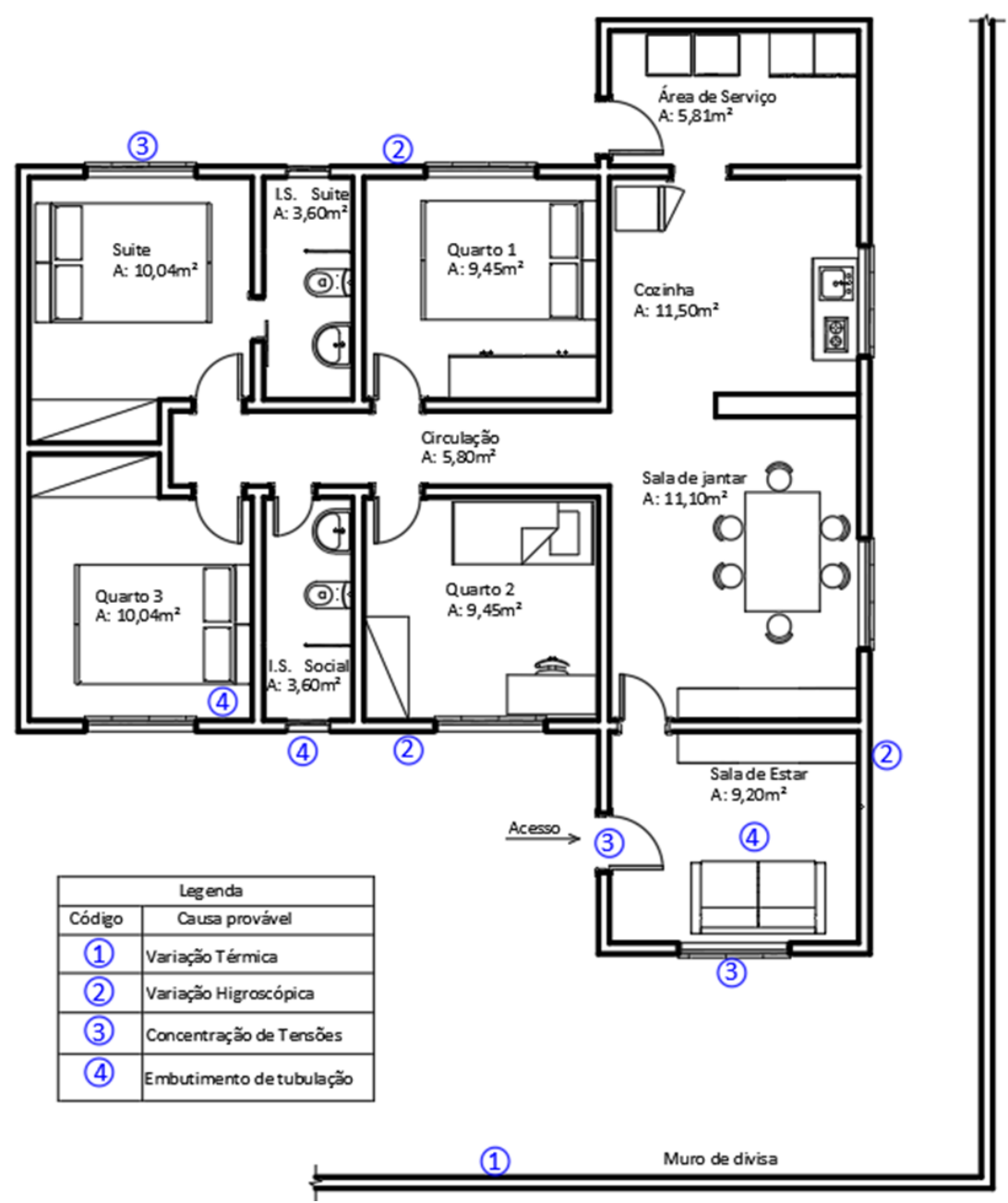

Figura 2. Croqui indicando os locais com as fissuras encontradas na edificação. Fonte: os autores.

\subsubsection{Fissuras causadas por variação térmica}

Na edificação estudada, o muro de divisa frontal, indicado pelo número 1 na Figura 2, é um dos elementos que mais recebe luz solar devido ao afastamento do restante da residência. A Figura 3 apresenta uma fissura geométrica que se propaga neste muro, direcionada segundo a argamassa de assentamento dos blocos.

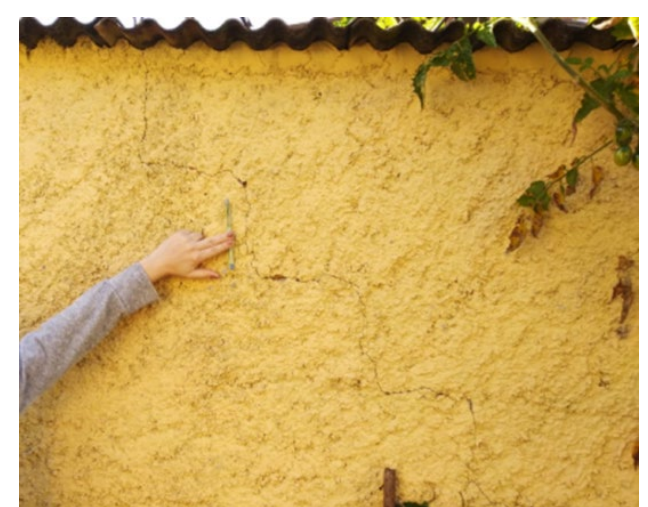

Figura 3. Trinca no muro frontal causada por variação térmica da estrutura. Fonte: os autores. 
Possivelmente, a manifestação patológica apresentada na Figura 3 é causada pela movimentação acentuada dos elementos do muro. Neste caso, a movimentação pode indicar recalque diferencial da estrutura ou sensibilidade à variação térmica. Entretanto, em uma análise realizada na edificação e no seu entorno não foram observados indícios de movimentação do solo e nem fissuras com a mesma característica. Desta forma, foi descartada a hipótese de recalque diferencial. Assim, é provável que a fissura ilustrada seja causada pela variação térmica do muro frontal.

As alterações climáticas ocasionam variações dimensionais nos materiais constituintes de uma edificação. Assim, os elementos mais expostos sentem de forma mais sensível a variação da temperatura e tendem a se movimentar mais (Duarte, 1998). O elemento de estudo neste item, o muro de divisa frontal, está exposto às ações do clima e não apresenta junta de dilatação para acomodar a movimentação dos materiais durante o processo de expansão e retração. Estes fatores podem contribuir para o aparecimento de fissuras e trincas, que normalmente surgem nos materiais de menor resistência.

\subsubsection{Fissuras causadas por variações higroscópicas}

A Figura 4 e Figura 5 apresentam fissuras geométricas horizontais formadas na base da alvenaria. As fissuras se localizam na fachada frontal e na fachada posterior, respectivamente, que possuem maior exposição às variações climáticas. A Figura 6, por sua vez, apresenta uma fissura localizada na fachada lateral direita do imóvel. A fissura possui uma configuração típica de fissura mapeada que se originou na argamassa de revestimento. As patologias apresentadas nestas figuras podem ser associadas à variação térmica ou higroscópica dos materiais e de seus componentes.

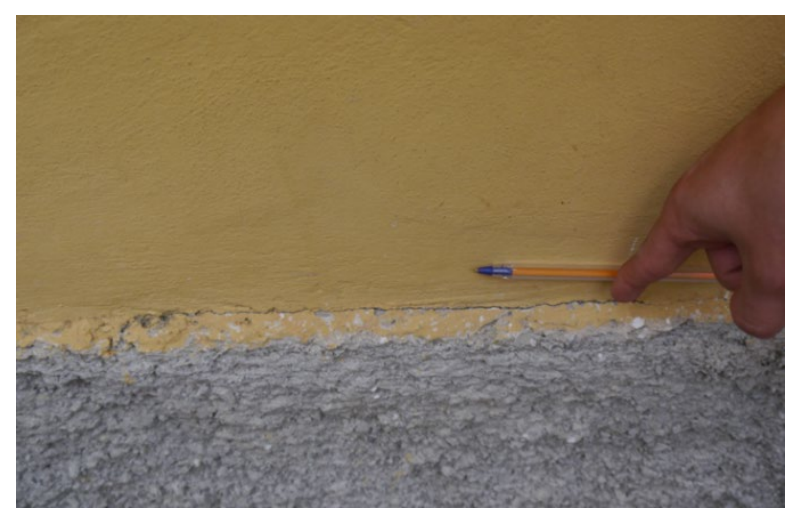

Figura 4. Fissura geométrica horizontal na base da alvenaria na fachada frontal. Fonte: os autores.

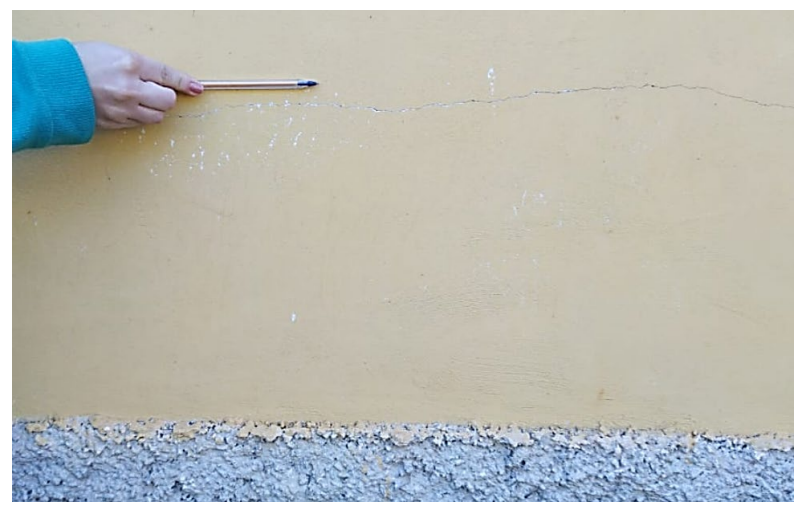

Figura 5. Fissura geométrica horizontal em camada inferior da alvenaria na fachada posterior. Fonte: os autores. 


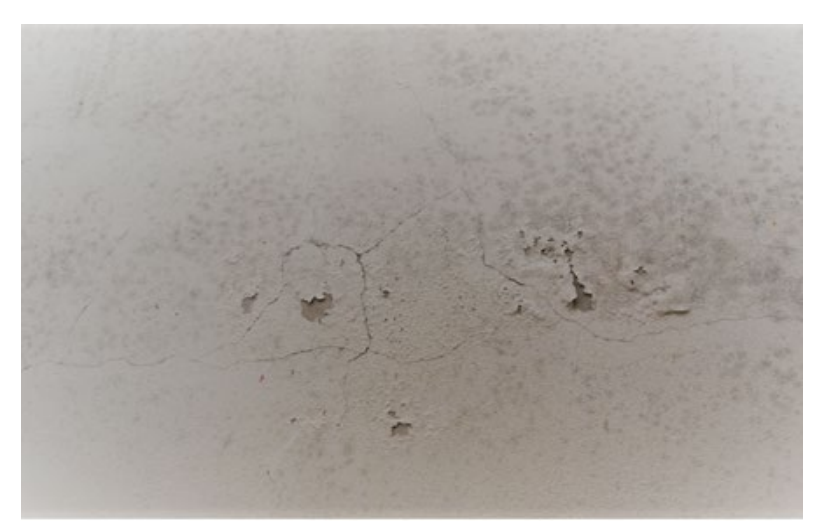

Figura 6. Fissura mapeada em argamassa de revestimento na fachada lateral direita do imóvel.

Fonte: os autores.

A proprietária do imóvel informou que a edificação não recebeu impermeabilização nas fundações, no contrapiso e na baldrame e tampouco nas primeiras fiadas de alvenaria. Somado a isto, ela ainda reiterou que durante a etapa de execução da obra foi constatado o afloramento de água em diversos pontos do terreno. Baseado nestas informações é possível inferir que a mais provável causa destas patologias é a movimentação higroscópica causada pela umidade.

Quando o alicerce da alvenaria não recebe adequada impermeabilização, as vigas baldrame e as primeiras fiadas de tijolos são afetadas pela umidade ascendente do solo (Thomaz, 1989; Exterckoetter \& Zancan, 2019). Por isso, as camadas inferiores da alvenaria absorvem a umidade e se movimentam de forma diferencial em relação às camadas superiores, originando as indesejáveis fissuras. Em geral, as fissuras que surgem devido à movimentação causada pela umidade são superficiais e frequentemente são acompanhadas por outras patologias, como eflorescência e desprendimento do revestimento. Na residência analisada, segundo a proprietária, alguns destes efeitos já foram observados logo nos primeiros anos de uso.

\subsubsection{Fissuras causadas por concentrações de tensões}

Outro tipo de fissura comumente encontrada nas edificações brasileiras foi identificado também na edificação de estudo: as fissuras que se desenvolveram nas bordas das esquadrias. A Figura 7 ilustra fissura inclinada em janela da sala de estar, locada na fachada frontal. A Figura 8 apresenta fissura inclinada em $45^{\circ}$ no bordo superior da porta da sala de estar.

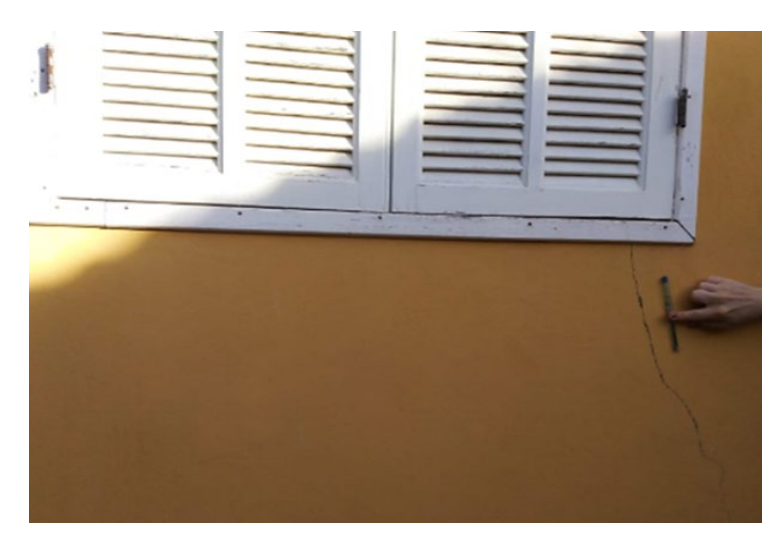

Figura 7. Fissura inclinada em aproximadamente $45^{\circ}$ na parte inferior do vão de janela. Fonte: os autores. 


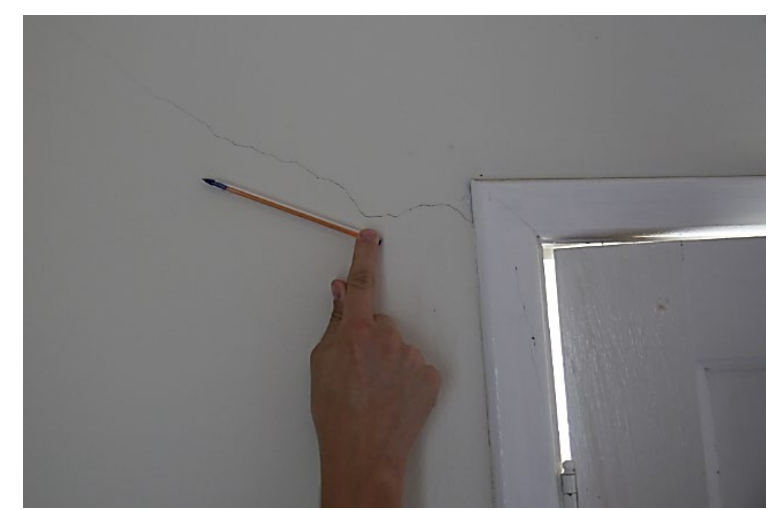

Figura 8. Fissura com inclinação próxima de $45^{\circ}$ localizada na parte superior do vão de porta. Fonte: os autores.

As fissuras apresentadas acima se propagaram, caracteristicamente, nas laterais dos vãos de esquadrias de portas e janelas. Estas fissuras podem estar associadas à existência de recalque diferencial da fundação, entretanto, essa hipótese foi descartada anteriormente devido à ausência de sinais de movimentação do solo e devido ao fato que as fissuras não possuem uma única direção predominante. Outra justificativa para a formação destas fissuras está na ausência de vergas e contravergas.

Segundo Thomaz (1989), em geral, os esforços resultantes do peso próprio, ação do vento, variação da temperatura e outros nas paredes sem aberturas se distribuem de maneira uniforme sobre a alvenaria. Entretanto, a abertura de vãos para as esquadrias faz com que estes esforços se redistribuam e se concentrem nas quinas e no centro das aberturas. Como resultado da concentração de tensões, podem aparecer fissuras nos cantos das esquadrias, formando ângulos aproximados de $45^{\circ} \mathrm{com}$ a horizontal, e no centro dos vãos, com direção vertical. Este fenômeno pode ser evitado com a utilização de vergas e contravergas, uma vez que estas promovem a adequada redistribuição das tensões nas proximidades das aberturas (Téchne, 2007).

De fato, na edificação estudada, não foram executadas vergas e contravergas nos vãos das esquadrias. Desta forma, não foram criados elementos capazes de resistir aos esforços gerados nas quinas e no centro das aberturas. Como resultado, os esforços atuantes na alvenaria, decorrentes do peso próprio e movimentação da estrutura, se concentram nestes pontos e são a provável causa destas fissuras inclinadas em $45^{\circ}$ e das fissuras verticais.

\subsubsection{Fissuras causadas por embutimento de tubulação na alvenaria}

As fissuras apresentadas neste subitem foram encontradas em locais onde provavelmente há passagem de tubulação, seja elétrica ou hidráulica. A Figura 9 apresenta uma fissura que se propaga na proximidade de um registro de torneira na parte externa da edificação, na fachada frontal. Já a Figura 10 apresenta uma fissura localizada no teto da sala de estar, próximo ao ventilador de teto. 


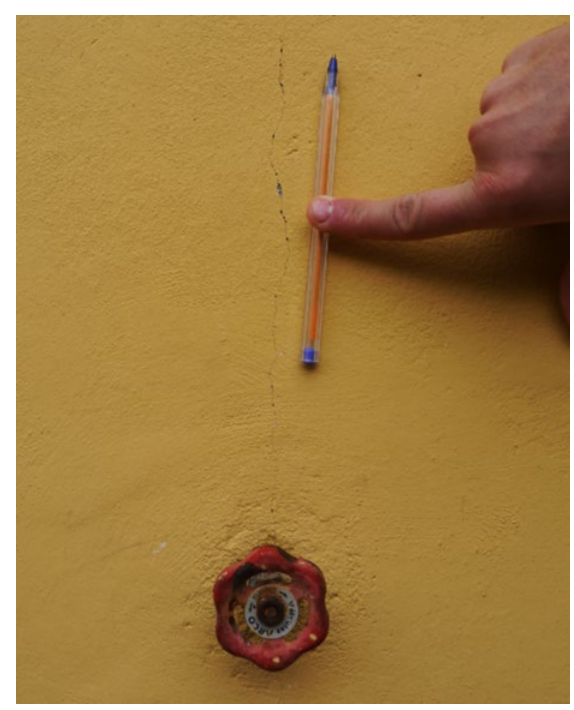

Figura 98. Fissura provavelmente causada pelo embutimento de tubulação hidráulica na alvenaria. Fonte: os autores

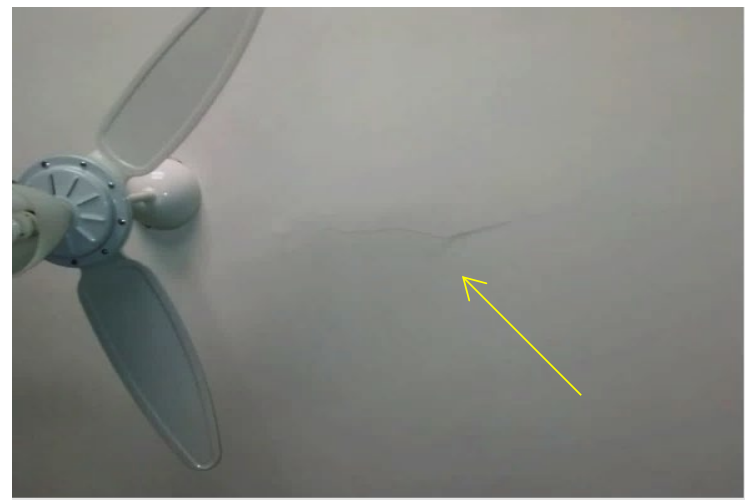

Figura 10. Fissura provavelmente causada pelo embutimento de tubulação elétrica no teto. Fonte: os autores.

Atualmente no Brasil, os tubos comumente utilizados para passagem de fios elétricos e do sistema hidrossanitário são embutidos nas alvenarias e lajes. Desta forma, por serem materiais menos rígidos que os blocos, estes tubos criam zonas de fraqueza (Téchne, 1998). Assim, quando os materiais se movimentam devido à variação higroscópica ou de temperatura, podem surgir fissuras nessas regiões. Estas patologias tendem a ser geométricas e a acompanhar o caminho da tubulação.

\subsection{Propostas de soluções técnicas}

Prever e evitar o surgimento de patologias construtivas durante a fase de projeto e execução da obra é sempre a solução mais efetiva. Por isso, é fundamental que o profissional técnico responsável pela obra conheça as patologias recorrentes e saiba como evitá-las ainda na etapa de construção da edificação. Entretanto, após a ocorrência de fenômenos patológicos, é necessária a adoção de soluções para combater o problema. A depender da causa da patologia e da solução empregada, é possível que o problema seja apenas minimizado e não solucionado por completo. Quanto à forma de recuperação, segundo Sahade (2005), existem três alternativas: substituição, reforço ou recuperação. No presente trabalho, o foco é na recuperação de elementos fissurados. A Tabela 1 apresenta um resumo das fissuras apresentadas neste estudo de caso e uma metodologia recomendada para a sua recuperação. 
Tabela 1. Causas das fissuras e respectivas sugestões de recuperação.

\begin{tabular}{|c|c|c|}
\hline Local onde foi encontrada & Causa provável & Metodologia recomendada \\
\hline Muro de divisa & Variação de temperatura & Aplicação de selante flexível \\
\hline Interface alicerce/alvenaria & Variação higroscópica & $\begin{array}{c}\text { Técnica com tela de metal } \\
\text { expandido }\end{array}$ \\
\hline Camada inferior da alvenaria & Variação higroscópica & Aplicação de selante flexível \\
\hline $\begin{array}{c}\text { Fissura na argamassa de } \\
\text { revestimento }\end{array}$ & Variação higroscópica & $\begin{array}{c}\text { Aplicação de tela de náilon e } \\
\text { tinta elástica }\end{array}$ \\
\hline $\begin{array}{c}\text { Vãos de esquadrias. } \\
\text { Concentração de tensões } \\
\text { contraverga }\end{array}$ & $\begin{array}{c}\text { Execução de verga e } \\
\text { Embutimento de } \\
\text { tubulação na alvenaria }\end{array}$ & $\begin{array}{c}\text { Inserção de barras de aço na } \\
\text { região onde passa a tubulação }\end{array}$ \\
\hline \begin{tabular}{c} 
Próximo à tomada, ventilador de teto hidráulico. \\
\hline
\end{tabular}
\end{tabular}

\subsubsection{Recuperação das fissuras causadas por variação de temperatura}

De acordo com Sahade (2005), a escolha do sistema de recuperação adequado é fundamental para que a fissura não ressurja com o tempo e deve ser compatível com o acabamento dos pontos vizinhos às patologias, de modo a não influenciar na arquitetura e estética da edificação. $\mathrm{O}$ objetivo deste procedimento é criar um componente capaz de absorver as solicitações oriundas da variação térmica. A recuperação de fissuras causadas por variação de temperatura, caso elas estejam limitadas à camada de revestimento, pode ser realizada com selantes flexíveis (Nascimento \& Cicuto, 2019). Segundo Thomaz (1989), estes selantes podem ser à base de poliuretano, silicone ou outros.

O processo de recuperação é iniciado pela abertura de uma lacuna retangular com $20 \mathrm{~mm}$ de largura e $10 \mathrm{~mm}$ de profundidade na fissura e limpeza da parede, removendo toda poeira e materiais resultantes do processo de desobstrução. Em seguida deve-se preencher a cavidade com selante flexível tixotrópico (Thomaz, 1989; Nascimento \& Cicuto, 2019). Por fim, executa-se um acabamento similar ao acabamento da área vizinha.

\subsubsection{Recuperação das fissuras causadas por variação higroscópica}

Para as fissuras situadas na interface alicerce/alvenaria é recomendável que seja utilizado sistema de recuperação com tela de metal expandido. A tela de metal expandido apresenta excelente resistência ao impacto e eficiente controle de fissuração (Chamelete, 1999). O passo inicial para a recuperação é remover o revestimento e limpar satisfatoriamente a superfície. Posteriormente deve-se estender a tela de modo a transpassar a fissura em $20 \mathrm{~cm}$ para cada lado e utilizar pregos ou grampos metálicos para fixá-la nos elementos.

Após a fixação, deve-se chapiscar a região aberta para dar aderência ao revestimento. Em seguida pode-se aplicar o reboco com argamassa com baixo módulo de deformação. Essa metodologia tem por objetivo travar o local do sistema de recuperação absorvendo os esforços e impedindo a movimentação dos elementos. A fissura mapeada apresentada na Figura 6 pode ser recuperada em três passos: remoção do revestimento danificado, inserção de bandagem ou tela de náilon no revestimento e posterior aplicação de tinta elástica com base acrílica. Entretanto, para que estas soluções sejam duráveis, é necessário antes desenvolver estratégias para limitar a ação da água no solo da edificação. 


\subsubsection{Recuperação das fissuras causadas por concentração de tensões}

As fissuras ocorridas nas proximidades das esquadrias podem ser solucionadas pontualmente, entretanto, a solução definitiva é a instalação de vergas e contravergas. Ambos os elementos devem ser maiores em comprimento que os vãos da alvenaria. Elas precisam transpassar a lacuna em $20 \%$ do comprimento do vão em cada lado, respeitando o mínimo de 30 centímetros (Sienge, 2018). Com relação à altura, é comum utilizar como pré-dimensionamento $10 \%$ do comprimento, porém, é essencial que seja feito cálculo normativo para determinar a dimensão correta.

\subsubsection{Recuperação das fissuras causadas por embutimento de tubulação na alvenaria}

Por fim, as fissuras instaladas nas proximidades de tubulações embutidas na alvenaria podem ser solucionadas de duas maneiras: com recuperação superficial ou pelo reestabelecimento do comportamento monolítico da alvenaria (Thomaz, 1989). A primeira opção consiste em aplicar bandagem ou tela de náilon no próprio revestimento e em seguida empregar tinta elástica com base acrílica. Nesta solução é preciso se atentar para não gerar uma superfície em alto relevo, desigual do acabamento.

Já a segunda alternativa, recomendada para o caso estudado, consiste em inserir barras de aço na região onde passa a tubulação. Neste caso, o procedimento de execução da técnica consiste em:

- Raspagem da argamassa de assentamento da alvenaria a uma profundidade aproximada de $15 \mathrm{~mm}$ e limpeza de forma a remover todo material raspado;

- Inserção de barras de aço de 4,2 ou 5,0 mm de diâmetro em ambos os lados da parede, com comprimento de transpasse aproximado de $25 \mathrm{~mm}$ para cada lado;

- Fixação das barras com argamassa seca;

- Execução do acabamento compatível com o local.

\section{CONCLUSÃO}

As fissuras geram sensação de desconforto e insegurança aos usuários das edificações. Além disso, podem resultar em infiltrações e indicar problemas estruturais. Com isto, as atividades de recuperação de fissuras ganharam maior relevância na construção civil e os valores gastos com tratamento dessas patologias também cresceram.

Neste trabalho, uma edificação unifamiliar construída entre os anos de 2008 e 2009 foi analisada. Foram identificadas fissuras oriundas das variações térmica e higroscópica nos elementos de alvenaria e de erros de execução da edificação. As manifestações patológicas identificadas são comumente encontradas em edificações brasileiras que, culturalmente, adotam a tática habitacional da autoconstrução.

Em entrevista realizada com a proprietária da edificação, verificou-se que era conhecida, antecipadamente à etapa de construção, a existência de fatores locais que poderiam originar patologias, como umidade e variação de temperatura elevadas. Porém, estes fatores não foram considerados na execução da edificação. Tal fato pode ser demonstrado pela ausência de impermeabilização dos elementos construtivos, de juntas de dilatação e de vergas e contravergas. Isto evidencia a necessidade e a importância da participação de um profissional capacitado em todas as etapas de construção, desde a concepção do projeto até a execução da obra. Além da presença de um profissional qualificado, é de suma importância, durante a execução da obra, criar metodologias que assegurem um adequado processo construtivo, por exemplo, a implantação de um sistema de qualidade.

Ainda que as patologias estudadas não comprometam a segurança estrutural da edificação, as mesmas geram desconforto e impactam financeiramente, na saúde e no psicológico dos usuários ao longo da vida útil da edificação. Assim, com os resultados obtidos, pode-se inferir que as fissuras podem ser minimizadas ou mesmo inibidas se realizado um acompanhamento adequado 
do processo construtivo e se adotadas técnicas e cuidados para prevenir o aparecimento destas manifestações patológicas. Desta forma, evita-se a necessidade de intervenções corretivas causadas por estas manifestações patológicas, reduzindo o gasto ao longo da vida útil da edificação.

\section{AGRADECIMIENTOS}

O presente trabalho foi realizado com apoio da Coordenação de Aperfeiçoamento de Pessoal de Nível Superior - Brasil (CAPES) - Código de Financiamento 001. Os autores também agradecem à FAPEMIG, CNPq, UFOP e UFJF pelo apoio para a realização e apresentação dessa pesquisa.

\section{REFERÊNCIAS}

Associação Brasileira de Normas Técnicas. (2013). NBR 15575-2 Edificações habitacionais Desempenho. Rio de Janeiro: Associação Brasileira de Normas Técnicas.

Chamelete, A. G. (1999). Armaduras para argamassa armada. São Paulo, Associação Brasileira de Cimento Portland, 2.ed.

Corsini, R. (Julho de 2010). Trinca ou fissura? Téchne(160).

Duarte, R. B. (Dezembro de 1998). Fissuras em alvenarias: causas principais, medidas preventivas e técnicas de recuperaão. $\operatorname{CIENTEC(25),~} 45$.

Exterckoetter, D. \& Zancan, E. C. (2019) Manifestação da patologia de umidade ascendente: estudo de caso da recuperação de uma residência unifamilar, Criciúma/SC. UNESC Universidade do Extremo Sul Catarinense.

Leonhardt, F., \& Monning, E. (1982). Construções de concreto - princípios básicos do dimensionamento de estruturas de concreto armado (Vol. 1). Rio de Janeiro: Interciência.

Lordsleem, A. C. (1997). Sistemas de recuperação de fissuras da alvenaria de vedação: avaliação da capacidade de deformação. Escola Politécnica da Universidade de São Paulo, São Paulo.

Nascimento, R. S., \& Cicuto, B. G. (2019). Fissuras e trincas em sistema de alvenaria de vedação: estudo de caso em unidade resisdencial. Revista Técnico-Científica do CREA$P R$.

Neves, M. B., \& Vázquez, E. G. (2020). Patologias das estruturas. Revista Boletim do Gerenciamento(22).

Oliveira, A. M. (2012). Fissuras, trincas e rachaduras causadas por recalque diferencial de fundações. Universidade Federal de Minas Gerais, Belo Horizonte. 
Possan, E., \& Demoliner, C. A. (Outubro de 2013). DESEMPENHO, DURABILIDADE E VIDA ÚTIL DAS EDIFICAÇÕES: ABORDAGEM GERAL. Técnico-Cientifica do CREA-PR ISSN 2358-5420(1), 14.

Ribeiro, E., \& Volkweis, F. J. (2016). Patologias em fachadas externas devido a movimentações higrotérmicas. Revista Tecnológica, 151-162.

Sahade, R. F. (2005). Avaliação de sistemas de recuperação de fissuras em alvenaria de vedação. Instituto de Pesquisas Tecnológicas do Estado de São Paulo, São Paulo.

Sienge. (2018). Vergas e Contravergas: garanta a segurança estrutural para suas obras. Acesso em 18 de Junho de 2020, disponível em Sienge: https://www.sienge.com.br/blog/vergascontravergas-cinta-de-amarracao/

Silva, F. B. (Setembro de 2011). Patologia das construções: uma especialidade na engenharia civil. Téchne(174), 3.

Souza, M. F. (2008). Patologias ocasionadas pela umidade nas edificações. . Universidade Federal de Minas Gerais . Belo Horizonte: Monografia (Especialização em Construção Civil: Avaliações e Perícias).

Souza, V. C., \& Ripper, T. (1998). Patologia, recuperação e reforço de estruturas de concreto. (1 ed.). São Paulo: Pini.

Téchne. (Setembro de 1998). As Causas de fissuras. Téchne(36).

Téchne. (Dezembro de 2007). Alvenaria sob ação horizontal. Téchne(129), 4.

Thomaz, E. (1989). Trincas em edifícios - causas, prevenção e recuperação (1 ed., Vol. 1). São Paulo: PINI: IPT.

Veiga, M. d. (1998). Comportamento de argamassas de revestimento de paredes. Faculdade de Engenharia da Universidade Do Porto. 